Research

\title{
Comparison of cisplatin sensitivity and the I 8F fluoro-2-deoxy 2 glucose uptake with proliferation parameters and gene expression in squamous cell carcinoma cell lines of the head and neck Eva Henriksson*1, Elisabeth Kjellén², Bo Baldetorp², Pär-Ola Bendahl2, Åke Borg2 ${ }^{2}$ Eva Brun², Fredrik Mertens ${ }^{3}$, Tomas Ohlsson ${ }^{4}$, Karin Rennstam², Johan Wennerberg ${ }^{5}$ and Peter Wahlberg 5
}

Address: ${ }^{1}$ Dept of Otorhinolaryngology, University Hospital Malmö, SE-205 02 Malmö, Sweden, ${ }^{2}$ Dept of Oncology, Lund University Hospital, SE-221 85 Lund, Sweden, ${ }^{3}$ Dept of Clinical Genetics, Lund University Hospital, SE-221 85 Lund, Sweden, ${ }^{4}$ Dept of Radiation Physics, Lund University Hospital, SE-221 85 Lund, Sweden and ${ }^{5}$ Dept of Otorhinolaryngology, Lund University Hospital, SE-221 85 Lund, Sweden

Email: Eva Henriksson* - Eva.Henriksson@skane.se; Elisabeth Kjellén - Elisabeth.Kjellen@med.lu.se; Bo Baldetorp - Bo.Baldetorp@med.lu.se; Pär-Ola Bendahl - Par-Ola.Bendahl@med.lu.se; Åke Borg - Ake.Borg@med.lu.se; Eva Brun - Eva.Brun@med.lu.se;

Fredrik Mertens - Fredrik.Mertens@skane.se; Tomas Ohlsson - Tomas.Ohlsson@skane.se; Karin Rennstam - Karin.Rennstam@med.lu.se; Johan Wennerberg - Johan.Wennerberg@skane.se; Peter Wahlberg - Peter.Wahlberg@skane.se

* Corresponding author

Published: 13 February 2009

Journal of Experimental \& Clinical Cancer Research 2009, 28:17 doi:10.1186/1756-9966-28-17
Received: 27 August 2008

Accepted: 13 February 2009

This article is available from: http://www.jeccr.com/content/28/I/I7

(C) 2009 Henriksson et al; licensee BioMed Central Ltd.

This is an Open Access article distributed under the terms of the Creative Commons Attribution License (http://creativecommons.org/licenses/by/2.0), which permits unrestricted use, distribution, and reproduction in any medium, provided the original work is properly cited.

\begin{abstract}
Background: The survival of patients with locally advanced head and neck cancer is still poor, with 5-year survival rates of $24-35 \%$. The identification of prognostic and predictive markers at the molecular and cellular level could make it possible to find new therapeutic targets and provide "taylor made" treatments. Established cell lines of human squamous cell carcinoma (HNSCC) are valuable models for identifying such markers.

The aim of this study was to establish and characterize a series of cell lines and to compare the cisplatin sensitivity and I8F fluoro-2 deoxy 2 glucose (I8F-FDG) uptake of these cell lines with other cellular characteristics, such as proliferation parameters and TP53 and CCNDI status.

Methods: Explant cultures of fresh tumour tissue were cultivated, and six new permanent cell lines were established from 18 HNSCC cases. Successfully grown cell lines were analysed regarding clinical parameters, histological grade, karyotype, DNA ploidy, and index and S-phase fraction (Spf). The cell lines were further characterized with regard to their uptake of I8F-FDG, their sensitivity to cisplatin, as measured by a viability test (crystal violet), and their TP53 and CCNDI status, by fluorescence in situ hybridization (FISH), polymerase chain reaction single-strand conformation polymorphism (PCR-SSCP) with DNA sequencing and, for cyclin DI, by immunohistochemistry.

Results: Patients with tumours that could be cultured in vitro had shorter disease-free periods and overall survival time than those whose tumours did not grow in vitro, when analysed with the Kaplan-Meier method and the log-rank test. Their tumours also showed more complex karyotypes than tumours from which cell lines could not be established. No correlation was found between TP53 or CCNDI status and I8F-FDG uptake or cisplatin sensitivity. However, there was an inverse correlation between tumour cell doubling time and I8F-FDG uptake.

Conclusion: In vitro growth of HNSCC cells seem to be an independent prognostic factor, with cell lines being more readily established from aggressive tumours, a phenomenon more dependent on the molecular genetic characteristics of the tumour cells than on tumour location or TNM status.
\end{abstract}




\begin{tabular}{|c|c|c|c|c|c|c|c|c|c|c|c|}
\hline Tumour & Take Rate & $\begin{array}{l}\text { Corresponding } \\
\text { cell line name }\end{array}$ & Site & $\mathbf{T}_{-}$stage & $\mathbf{N}_{\text {_ stage }}$ & M_ stage & Stage & Grade & $\begin{array}{c}\text { Flowcyto } \\
\text { Metry }\end{array}$ & DNA_indices & Cytogenetics \\
\hline I & yes & LU-HNxSCC-3 & 310 & 4 & 0 & 0 & 4 & G3 & diploid & 1 & not complex \\
\hline 2 & yes & LU-HNxSCC-6 & 021 & 3 & 0 & 0 & 3 & G3 & nondiploid & 1,25 & complex \\
\hline 3 & yes & LU-HNxSCC-8 & 060 & 2 & 1 & 0 & 3 & G3 & nondiploid & 1,9 & complex \\
\hline 4 & yes & LU-HNxSCC-4 & 040 & 2 & 0 & 0 & 2 & G3 & nondiploid & $\mathrm{I}, 85$ & complex \\
\hline 5 & yes & LU-HNxSCC-5 & 062 & 2 & $2 b$ & 0 & 4 & $\mathrm{G} 2$ & nondiploid & 2,38 & complex \\
\hline 6 & yes & LU-HNxSCC-7 & 060 & 2 & 0 & 0 & 2 & $\mathrm{G} 2$ & diploid & I & complex \\
\hline 7 & no & & 021 & 2 & 0 & 0 & 2 & $\mathrm{G} 2$ & nondiploid & 1,9 & failure \\
\hline 8 & no & & 119 & 1 & 0 & 0 & 1 & G3 & nondiploid & 1,22 & failure \\
\hline 9 & no & & 321 & 3 & 1 & 0 & 3 & G3 & diploid & I & not complex \\
\hline & & & & & & & & & & & \\
\hline 10 & no & & 040 & 2 & $2 c$ & 0 & 4 & $\mathrm{G} 2$ & nondiploid & $\mathrm{I}, 87$ & complex \\
\hline II & no & & 090 & 3 & 0 & 0 & 3 & Gx & diploid & 1 & failure \\
\hline 12 & no & & 322 & 4 & 0 & 0 & 4 & G2 & nondiploid & 1,93 & failure \\
\hline 13 & no & & 119 & 2 & $2 a$ & 0 & 4 & G4 & diploid & 1 & failure \\
\hline 14 & no & & 139 & 2 & $2 c$ & 0 & 4 & G2 & nondiploid & 1,28 & missing \\
\hline 15 & no & & 321 & 4 & $2 b$ & 0 & 4 & G3 & nondiploid & 1,59 & complex \\
\hline 16 & no & & 320 & 4 & 0 & 0 & 4 & $\mathrm{G} 2$ & diploid & 1 & failure \\
\hline 17 & no & & 770 & 0 & $2 b$ & 0 & 4 & G2 & nondiploid & $\mid, 5 \mathrm{I}$ & failure \\
\hline 18 & no & & 040 & 1 & $2 a$ & 0 & 4 & $\mathrm{G} 2$ & diploid & 1 & complex \\
\hline
\end{tabular}




\section{Background}

In 2006, 101,600 new cases and 42,400 deaths resulting from oropharyngeal cancer were registered in Europe [1]. Although morbidity has decreased, the outcome of patients with locally advanced head and neck cancer is still poor, 5-year survival rates being only $24-35 \%[2,3]$. There is a need for more individualized, "taylor-made" therapies in order to avoid under-treatment (residual disease) as well as over-treatment (unnecessary morbidity). The application of new techniques has improved our understanding of the mechanisms behind the origin, maintenance and progression of tumours, and new insights have facilitated the identification of diagnostic, prognostic and predictive markers at molecular and cellular levels, paving the way for novel therapeutic approaches.

Cell lines of human squamous cell carcinoma are valuable models for identifying such markers, and for studies of tumour biology. In this study, explant cultures of fresh tumour tissue were cultivated and six new permanent cell lines were established from 18 patients with head and neck squamous cell carcinoma (HNSCC). The cell lines established in this study were used to test for cisplatin sensitivity, 18F-FDG uptake, as a measure of metabolic activity, and various other tumour characteristics.

\section{Methods \\ Patients}

Fresh tumour samples were collected during 1995-1999 from 18 patients with HNSCC. The patients participated voluntary and with informed consent. Seventeen of the 18 patients with HNSCC were previously untreated and one patient had a residual tumour after radiotherapy. Eight tumours were located in the oral cavity, four in the larynx, two in the nasopharynx, and one each in the oropharynx, hypopharynx and in the maxillary sinus. One was an untreated lymph node metastasis of unknown primary origin. Table 1 shows the tumour TNM (Tumour, Node, Metastasis) classification, stage, grade, ploidity and karyotype of each tumour. Permanent cell lines were successfully established from the first six tumours in Table 1; four were from the oral cavity, one from the maxillary sinus and one was a residual tumour from the oral cavity. Table 2 shows clinical information regarding treatment regim, survival data and causes of death.

\section{Establishment of cell lines}

Fresh tumour tissue samples obtained during surgery were immersed immediately in buffered balanced saline. The tissues were washed several times, trimmed and minced into 1 to $2 \mathrm{~mm}$ pieces, which were placed in T25 tissue culture flasks with DMEM supplemented with $2 \mathrm{mM} \mathrm{L-}$ glutamine and $10 \%$ foetal bovine serum (FBS). The flasks were incubated at $37^{\circ} \mathrm{C}$ in an atmosphere containing $5 \%$ carbon dioxide. Primary tissue culture flasks were observed daily. To reduce the fibroblast growth, DMEM D-valine was added instead of L-valine. Fibroblasts were also removed mechanically and by brief exposure to trypsin $(0.1 \%)$ and EDTA $(0.02 \%)$. Tumour cells were subcultured when the flasks were 50\% confluent. After three or four passages the cells were stored in liquid nitrogen. Low passage numbers $(<30)$ were used for this study.

\section{Growth characteristics}

The cell lines were denoted LU-HNSCC 3 to 8 . All cell lines had an epitheloid appearance, and grew in a typical cobblestone pattern indicating squamous cell carcinoma origin. The cells differed in size and grew in colonies with cell-to-cell contact into confluence. All cell lines, besides number 6 , grew as monolayer cultures and were easy to detach using trypsin; cells from LU-HNSCC 6 were more difficult to detach and to grew in multiple layers.

\section{Growth rate}

To determine the in vitro tumour cell growth rate, 15,000100,000 cells were plated in Petri dishes, and the number of cells was counted every second day in a Bürker chamber. The growth rate for each cell line was determined at least twice and the results were found to be reproducible. The mean values of 2-5 samples were estimated. The doubling times were derived from the exponential growth phase, and are given in Table 3, together with other data.

\section{Tumorigenicity in nude mice}

To verify the malignancy of the established cell lines in vitro, a cellsolution containing the same cell amount from each cell line were injected subcutaneously into the lateral thoracic wall of nude mice. Tumour formation was observed for all cultured cell lines. The purpose of this experiment was to confirm the malignant characteristics of the cultured cell lines and to exclude a fibroblast cell population. The tumour formations in nude mice were no further examined in this experiment. The study was approved by the Regional Ethics Board of Southern Sweden Committe(LU376-01, M48-06).

\section{Flow cytometry}

Frozen samples from 16 biopsies from primary tumours were analysed, and two samples from formalin-fixed and paraffin-embedded specimens were also analysed. Flow cytometry DNA analysis was performed as previously described [4]. Briefly, the tumour samples were minced, forced through a nylon net (pore size $140 \mu \mathrm{m}$, Tidbeck $\mathrm{AB}$, Stockholm, Sweden), and fixed in $70 \%$ ethanol. The two formalin-fixed samples were processed to form cell suspensions according to a previously described method [5]. 
Table 2: The features of the primary tumours regarding treatment regime, follow up time and cause of death.

\begin{tabular}{|c|c|c|c|c|c|c|c|c|c|}
\hline Tumour & $\begin{array}{l}\text { Take } \\
\text { Rate }\end{array}$ & $\begin{array}{l}\text { Corresponding } \\
\text { cell line }\end{array}$ & Site & Surgery & $\begin{array}{l}\text { Radiation- } \\
\text { therapy }\end{array}$ & $\begin{array}{l}\text { Disease free } \\
\text { months }\end{array}$ & $\begin{array}{l}\text { Overall } \\
\text { survival In } \\
\text { months }\end{array}$ & $\begin{array}{l}\text { Death caused } \\
\text { by intercurrent } \\
\text { disease }\end{array}$ & $\begin{array}{l}\text { Death } \\
\text { caused by } \\
\text { HNSCC }\end{array}$ \\
\hline I & yes & LU-HNxSCC-3 & 310 & No & Yes & 0 & 12 & No & Yes \\
\hline 2 & yes & LU-HNxSCC-6 & 021 & Yes & Yes & 6 & 8 & no & Yes \\
\hline 3 & yes & LU-HNxSCC-8 & 060 & Yes & Yes & 2 & 4 & Yes & No \\
\hline 4 & yes & LU-HNxSCC-4 & 040 & Yes & Yes & 37 & 42 & yes & No \\
\hline 5 & yes & LU-HNxSCC-5 & 062 & No & Yes & 4 & 4 & No & Yes \\
\hline 6 & yes & LU-HNxSCC-7 & 060 & Yes & yes & 19 & 25 & no & Yes \\
\hline 7 & no & & 021 & Yes & No & 0 & 1 & Yes & No \\
\hline 8 & no & & 119 & No & Yes & 25 & 43 & No & Yes \\
\hline 9 & no & & 321 & No & No & 0 & I & No & Yes \\
\hline 10 & no & & 040 & Yes & Yes & 74 & 96 & No & Yes \\
\hline II & no & & 090 & No & Yes & 99 & 108 & No & No \\
\hline 12 & no & & 322 & Yes & Yes & 85 & 87 & Yes & No \\
\hline 13 & no & & 119 & No & Yes & 90 & 108 & No & No \\
\hline 14 & no & & 139 & No & Yes & 0 & 78 & No & Yes \\
\hline 15 & no & & 321 & Yes & Yes & 66 & 75 & No & Yes \\
\hline 16 & no & & 320 & Yes & Yes & 8 & I & Yes & No \\
\hline 17 & no & & 770 & Yes & Yes & 113 & 122 & No & No \\
\hline 18 & no & & 040 & yes & yes & 98 & 108 & no & no \\
\hline
\end{tabular}

The separated cells were then treated with ribonuclease (Sigma-Aldrich, Stockholm, Sweden), incubated with pepsin (Merck, Darmstadt, Germany), and stained with propidium iodide (Sigma-Aldrich, Stockholm). Human lymphocytes were processed in parallel with the tumour samples and used as an external diploid control for the fresh samples. Flow cytometric DNA analysis was performed in a FACS Caliber (Becton, Dickinson, BD Biosciences, USA). Up to 20,000 nuclei were analysed from each sample. The DNA histograms obtained were automatically processed using Modfit LT 3.1 ${ }^{\mathrm{TM}}$ software. The DNA index (DI) was calculated as the ratio of the modal channel values of the G0 and G1 peaks. By definition, the tumours manifesting a single DNA population were clas- sified as diploid (i.e. DI =1.00), and tumours manifesting two or more populations as non-diploid. The S-phase fraction (Spf) was estimated assuming that the S-phase compartment constituted a rectangular distribution between the modal values of the G0/G1 and G2 peaks.

\section{Chromosome banding analysis}

Fresh samples from all but one of the 18 primary tumours previously had been subjected to short-term culturing and G-banding analysis [6]. All six established cell lines were also cytogenetically analysed using the same methods as in the present study. 
Table 3: Characteristics of the established cell lines regarding cisplatin sensitivity and cell doubling time.

\begin{tabular}{lll}
\hline Cell line Name & Cisplatin IC50 & Cell doubling time \\
\hline LU-HNxSCC & $(\mu \mathrm{M}) *$ & $($ Days $) * *$ \\
\hline 3 & $24,8 \pm 6,4$ & $1,8 \pm 0,4$ \\
\hline 4 & $6 \pm 0,9$ & $1,1 \pm 0,1$ \\
\hline 5 & $29,2 \pm 3,1$ & $1,6 \pm 0,2$ \\
\hline 6 & $16,5 \pm 4,5$ & $1,3 \pm 0,4$ \\
\hline 8 & $11,3 \pm 3,5$ & $2,2 \pm 0,2$ \\
\hline
\end{tabular}

* cisplatin sensitivity is the mean of 3-6 experiments \pm SEM and

studied passage number $10-30$

** cell doubling time is the mean values from two or more

experiments and studied passage number $5-26$

\section{Immunohistochemistry}

Immunohistochemical (IHC) analysis was performed on paraffin-embedded specimens to detect cyclin D1 (CCND1) expression. A commercial monoclonal antibody (NCL-cyclin D1, Novo) was used at a dilution of 1:20. A specimen known to be strongly positive, previously collected from a patient, was used as a positive control. The IHC results were scored as follows: A-negative; $\mathrm{B}$ $1-5 \%$ of the tumour cells positive; C $6-50 \%$ positive; D $>50 \%$ positive. The negative controls were tested without primary antibodies.

\section{Fluorescence in situ hybridization}

Fluorescence in situ hybridization (FISH) was performed as previously described [7], with minor modifications. Briefly, tumour cells were spread onto Superfrost Plus slides (Menzel, Braunschwieg, Germany), and then air dried and fixed in a series of 50, 75 and 100\% Carnoy's solution (100\% Carnoy's = 3:1 methanol:acetic acid). Prior to hybridization, the slides were denatured in $70 \%$ formamide, $2 \times \mathrm{SSC}, \mathrm{pH} 7.0$, at $72^{\circ} \mathrm{C}$ for three minutes, and dehydrated in a series of ethanol solutions (70, 85 and $100 \%$ ). Two-colour FISH was performed with directly labelled probes for CCND1 and the centromere of chromosome 11 (LSI Cyclin D1 spectrum orange TM/CEP 11 spectrum green TM DNA Probe; Vysis, Inc., Downers Grove, IL, USA). Slides were counterstained with $0.2 \mathrm{mM}$ 4,6-diamidino-2-phenylindole in an antifade solution (Vectashield, Vector H1000; Vector Laboratories, Burlingame, CA, USA) in order to visualize the nuclei and to prevent the fluorochromes from fading. A Zeiss Axioplan 2 microscope (Carl Zeiss AG, Oberkochen, Germany), equipped with a cooled CCD camera (Sensys; Photomet- rics, Tucson, NV, USA), operated by Quips FISH image analysis software (Vysis, Inc.) was used to analyse the samples. Hybridization signals from at least 50 nuclei were scored to assess the centromere and CCND1 copy numbers. The nuclei were defined as carrying an amplification if the number of gene probe signals divided by the number of centromere signals was $\geq 1.5$.

\section{PCR-SSCP and DNA sequencing}

Polymerase chain reaction-single-strand conformation polymorphism (PCR-SSCP) analysis and DNA sequencing were used to study the occurrence of mutations in exons 4-11 of TP53, as previously described [8]. Briefly, DNA was extracted using standard methods and used in a polymerase chain reaction to amplify the entire coding region of the TP53 gene in seven or eight different fragments. The PCR products were screened for mutations using SSCP. Samples showing altered mobility shift in SSCP were further analysed with direct DNA sequencing to determine the exact location and type of mutation.

\section{Cisplatin-induced cell death}

The cell lines LU-HNSCC 3-8 were harvested by trypsinization, counted and seeded (10,000-26,000 cells/well) in 24-well plates, and allowed to grow for two days as monolayer cultures in DMEM medium (GIBCO, San Diego, CA, USA), supplemented with $10 \%$ FBS and antibiotics (100 U/ml streptomycin sulphate, GIBCO), under a 5\% $\mathrm{CO}_{2}$ atmosphere at $37^{\circ} \mathrm{C}$. On day two, cisplatin (Pharmalink $A B$, Upplands Väsby, Sweden) was added in serumfree medium, and the cells were incubated for $1 \mathrm{~h}$ at concentrations ranging from 0 to $100 \mu \mathrm{M}$. Thereafter, the drug-containing medium was removed, and cells were allowed to grow in drug-free medium for 5 days. On day 7 , the cell viability was estimated by the crystal violet

assay, as described previously [9]. Briefly, the cells were incubated with $0.5 \%$ crystal violet (methanol:water, $1: 4$ ) and excess dye was removed. The cells were solubilized by the addition of $0.10 \mathrm{M}$ citrate buffer (SIGMA) (50\% (v/v) ethanol) and then transferred to a new 96-well plate, and the absorbance was determined spectrophotometrically at $570 \mathrm{~nm}$ on a Multiscan MS (Labsystems, Finland) and corrected for background absorbance.

\section{I8F-FDG measurements}

The established cell lines LU-HNSCC 3-8 were harvested by trypsinization, counted and seeded (50,000-250,000 cells/Petri dish) on day 0 . The cells were allowed to grow for two days as monolayer cultures in DMEM medium(GIBCO, San Diego, CA) supplemented with $10 \%$ heat-inactivated FBS containing an antibiotic (GIBCO)(100 U/ml streptomycin sulphate), under a 5\% $\mathrm{CO}_{2}$ atmosphere at $37^{\circ} \mathrm{C}$. On day three, $2 \mathrm{ml} 18 \mathrm{~F}-\mathrm{FDG}$ solution $(0.62-1.33 \mathrm{MBq} / \mathrm{ml})$ was added. After an hour 
the solution was removed by aspiration. The Petri dishes with cells were rinsed three times with PBS. The cells were then harvested from the Petri dishes by trypsinization and neutralized with $4 \mathrm{ml}$ medium, and collected as samples for 18F-FDG determination together with the discarded 18F-FDG solution.

The 18F-FDG uptake in the cells and in the washing fractions was estimated using a calibrated 3 x 3 inch NaI(TI) well counter (in house) (1282 CompuGamma CS, LKB Wallac, Turku, Finland) and all 18F-FDG values were normalized for time. Electronic cell counting was performed using a NucleoCounter ${ }^{\mathrm{TM}}$ (Chemotec A/S, Allerod, Denmark) with the NucleoView ${ }^{\mathrm{TM}}$ software. The total cell content and number of viable cells were calculated per $\mathrm{ml}$ and correlated to the 18F-FDG uptake corrected for decay. This experiment was repeated in a second series.

\section{Statistics}

Descriptive statistics, Fisher's exact test, and the chisquared test for trend, were used to evaluate differences in clinical parameters between patients whose tumours could be cultured, and those that could not. Disease-free periods and overall survival time in these groups were examined using Kaplan-Meier graphs and log-rank tests (SPSS for Windows version 14.0, Chicago, IL, USA). The degree of linear relationship between pairs of variables measured on a continuous scale was summarized using correlation ( $\mathrm{r}$ ) and a test for zero slope in a corresponding linear regression model. Kruskal-Wallis' test was used to test the null hypothesis of equal cisplatin sensitivity for the cell lines. For comparison of 18F-FDG uptake between the cell lines, the following multiple linear regression model was used:

$$
\begin{gathered}
F D G=c_{1}+b_{1} V+c_{2} I_{2}+b_{2} I_{2} V+c_{3} I_{3}+b_{3} I_{3} V+c_{4} I_{4}+b_{4} I_{4} V+ \\
c_{5} I_{5}+b_{5} I_{5} V+c_{6} I_{6}+b_{6} I_{6} V
\end{gathered}
$$

where the dependent variable $18 \mathrm{~F}-\mathrm{FDG}$ is $18 \mathrm{~F}-\mathrm{FDG}$ uptake and the independent variables are:

$\mathrm{V}=$ Number of viable cells

five dummy variables contrasting cell lines $2-6$ to cell line 1:

$I_{j}=1$ if cell line $=j, j=2-6$

$I_{j}=0$ otherwise

and five interaction parameters (products):

$\mathrm{I}_{\mathrm{j}} \mathrm{V}=\mathrm{V}$ if cell line $=\mathrm{j}, \mathrm{j}=2-6$

$\mathrm{I}_{\mathrm{j}} \mathrm{V}=0$ otherwise
This linear model has 12 parameters with the following interpretation:

$\mathrm{c}_{1}$ : Intercept for the reference cell line (1)

$\mathrm{b}_{1}$ : Slope for the reference cell line (1)

$\mathrm{c}_{\mathrm{j}}$ : Intercept difference between cell line $\mathrm{j}$ and the reference cell line, $j=2-6$

$\mathrm{b}_{\mathrm{j}}$ : Slope difference between cell line $\mathrm{j}$ and the reference cell line, $\mathrm{j}=2-6$

In this modelling framework, an F-test was used to test the null hypothesis of equal 18F-FDG uptake for the cell lines at a fixed number of viable cells. The packages SPSS 14.0 (Chicago, IL, USA) and Stata 10.0 (StataCorp 2007, College Station, TX, USA) were used for statistical analysis.

\section{Results \\ Patients: primary tumour characteristics and clinical course}

Six new permanent squamous cell carcinoma lines in vitro were established from 18 HNSCCs, which constitutes an overall success rate of $33 \%$.

The overall survival of the patients as a function of the propensity of their tumours to grow in vitro, calculated from date of diagnosis, is shown in Figure 1. The outcome for the patients from whom cell lines could be established was worse than for the other patients; the median overall survival being 8 vs. 78 months ( $\mathrm{p}=0.009$; logrank test), and the fraction of 5 -year survival 0 vs. $67 \%$. The mean disease-free survival time was 13 months for the patients whose tumours grew as cell lines, compared with 80 months for those whose cancers did not grow in vitro $(\mathrm{p}=$ $0.056)$. No differences were observed in the two groups regarding tumour site, TNM status, stage, grade, ploidity or DNA indices (data not shown).

\section{Chromosome banding analysis}

Five of the six tumours that grew as cell lines had complex karyotypes, defined here as at least three different aberrations, when examined after short-term culturing. In contrast, only three of the 11 tumours from which no cell line could be established, and from which material had been sent for short-term culturing, had complex karyotypes. The remaining eight cases either failed to grow in vitro (seven cases), or showed an abnormal karyotype with simple changes (one case). There was no aberration in common among the tumours that yielded viable cell lines, and it was noted that none of them displayed homogeneous staining regions. Only minor changes were noted when comparing the karyotypes obtained after 


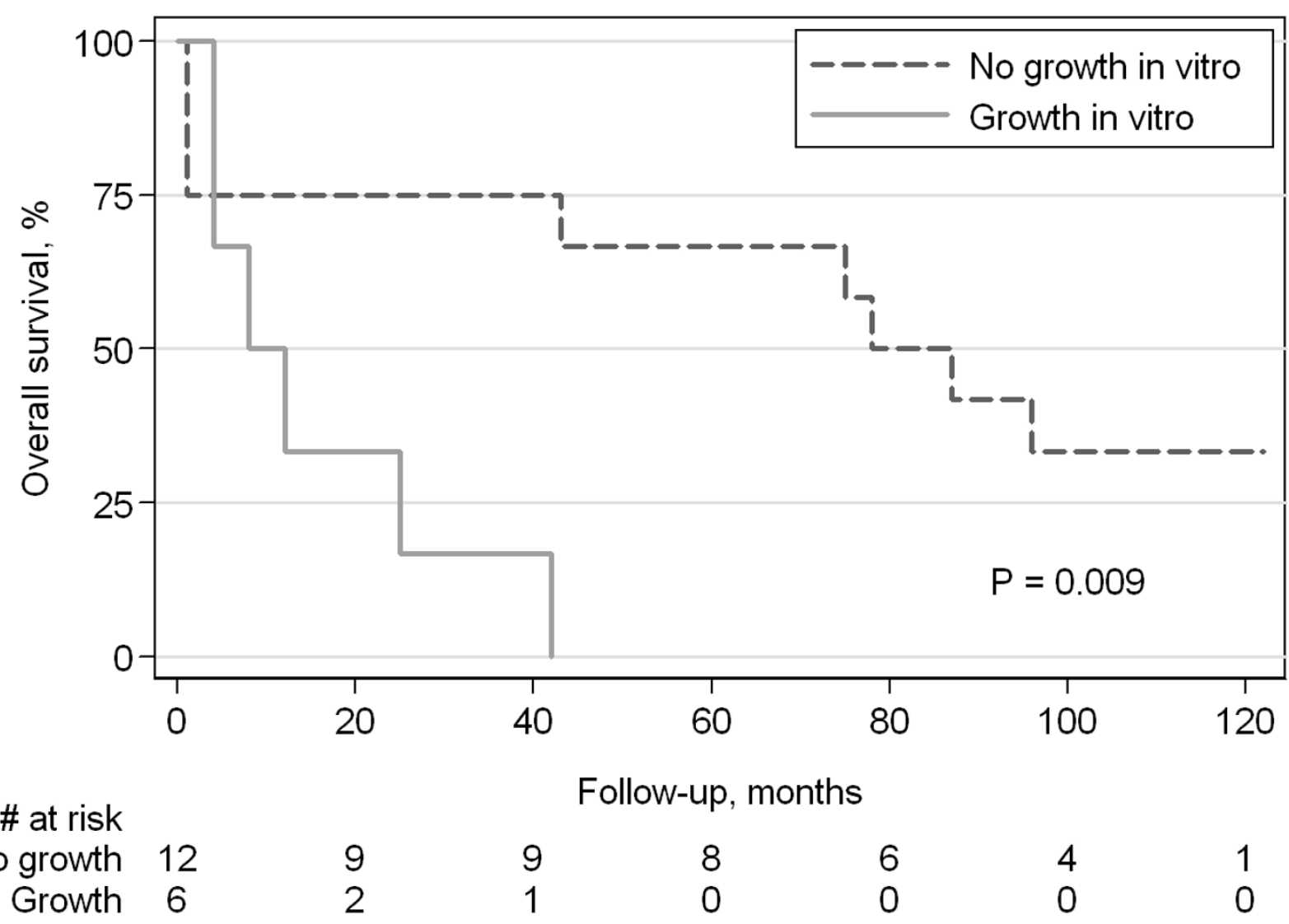

Figure I

Overall survival of the patients stratified by propensity of their tumours to grow in vitro. Survival times were calculated from date of diagnosis. Four patients were still alive (survival >100 months) when this analysis was carried out.

short-term culturing of primary tumours and in the corresponding cell lines (data not shown).

\section{The established cell lines}

Three cell lines showed TP53 mutations, two in exon 7 and one in exon 5 (Table 4). Two of the mutations, one in exon 5 and one in exon 7 , were missense mutations, and one in exon 7 was a deletion. Two of the three cell lines with TP53 mutation also showed CCND1 overexpression; one of these had CCND1 amplification according to FISH. No cell line showed CCND1 amplification without TP53 mutation.

\section{8F-FDG uptake}

The 18F-FDG uptake, expressed as counts per minute (cpm) adjusted for time, was strongly correlated with the number of viable cells present, as illustrated in Figure 2. The correlations varied between 0.94 (LU-HNSCC 3) and
0.99 (LU-HNSCC 7). The null hypothesis of no difference in 18F-FDG uptake between the cell lines was evaluated in a linear regression framework (see Statistics) and according to this model, the predicted 18F-FDG uptake for $1,000,000$ viable cells varied more than a factor 2 , from $65,000 \mathrm{cpm}$ for LU-HNSCC 3 to $133,000 \mathrm{cpm}$ for LUHNSCC 6 . The null hypothesis of equal 18F-FDG uptake for this fixed number of viable cells could be rejected ( $\mathrm{p}<$ 0.0001 ; F-test). Significant differences in 18F-FDG uptake between the cell lines $(\mathrm{p}<0.01)$ was seen for all reference values from 50,000 to $1,500,000$ viable cells and also in sub-group analyses excluding one of the two cell lines with non-overlapping ranges for number of viable cells.

No correlation was observed between 18F-FDG uptake or gene expression and cell characteristics, such as TP53 and CCND1 status or DNA ploidity. 
Table 4: Characteristics of the established cell lines regarding proliferation parameters, DNA content and gene expression.

\begin{tabular}{|c|c|c|c|c|c|c|c|}
\hline Cell line & $\begin{array}{l}\text { Flowcytometry } \\
(n=I)\end{array}$ & & & $\begin{array}{l}\text { Immunohistochemistry } \\
(n=3)\end{array}$ & $\begin{array}{l}\text { PCR_SSCP } \\
(n=I)\end{array}$ & $\begin{array}{l}\text { FISH } \\
(n=I)\end{array}$ & $\begin{array}{l}\text { Cytogenetics } \\
(\mathrm{n}=1)\end{array}$ \\
\hline LU-HNxSCC & Ploidity & DNA indices & S\%phase & Cyclin DI & Tp53 & Cyclin D I & \\
\hline 3 & Diploid (p4) & I & ND* & $A$ & 0 & 0 & not complex \\
\hline 4 & Nondilploid (p22) & 1,4 & 26,3 & C & exon7 R249G & 0 & complex \\
\hline 5 & Nondiploid (p27) & 2,1 & 23,8 & $\mathrm{D}$ & exon5 HI68P & ++ & complex \\
\hline 6 & Nondiploid (p20) & $\mathrm{I}, 2$ & 16 & $A$ & 0 & 0 & complex \\
\hline 7 & Nondiploid (p6) & $\mathrm{I}, 4$ & 9,8 & $A$ & 0 & deletion & complex \\
\hline 8 & Nondiploid (p22) & 1,6 & 22,2 & $\mathrm{~B}(\mathrm{I} / 3 \mathrm{C})$ & exon7 Ldel252 & $1 / 3+$ & complex \\
\hline
\end{tabular}

$* \mathrm{ND}=$ not determined

We found an inverse correlation $(\mathrm{r}=-0.82)$ between cell doubling time (DT) and 18F-FDG uptake; the shorter the doubling time, the higher the 18F-FDG uptake $(\mathrm{p}=0.04$; test for zero slope in a linear regression of predicted $18 \mathrm{~F}-$ FDG uptake at 1,000,000 viable cells on doubling time; $\mathrm{n}$ $=6)$.

This inverse relationship was even stronger if the cell line LU-HNSCC 3 with no observations above 600,000 viable cells was omitted $(r=-0.95 ; p=0.01)$ or if the cell line LUHNSCC 7 with no observations below 700,000 viable cells was omitted and the 18F-FDG uptake was predicted for 500,000 viable cells $(r=-0.96 ; p=0.01)$. The experiment was repeated with similar results.

In brief, the correlations between 18F-FDG uptake and number of viable cells varied from 0.81 to 0.98 and the predicted $18 \mathrm{~F}$-FDG uptake at 1,000,000 viable cells varied significantly between the cell lines also in the second experiment $(\mathrm{p}<0.0001)$. Also the negative correlation between 18F-FDG uptake and DT was reproduced in the second series $(r=-0.70 ; p=0.12 ; n=6)$. By combining the data from the two experiments, the p-value for the inverse correlation between 18F-FDG uptake and DT dropped to 0.004 .

\section{Cisplatin sensitivity}

The cisplatin sensitivity of the different cell lines is illustrated in Figure 3. Significant differences in cisplatin sensitivity between the cell lines was seen at 5, 50 and $100 \mu \mathrm{M}$ ( $\mathrm{p}<0.0001$; Kruskal-Wallis test). The values of $\mathrm{IC}_{50}$ for the different cell lines varied between 6 and $29 \mu \mathrm{M}$. The cisplatin sensitivity did not show any relationship with TP53 mutations, CCND1 amplification or overexpression, or tumour doubling time.

\section{Discussion}

In accordance with other studies [10-12], we found that tumours that could grow in vitro were more aggressive in their biological behaviour, with shorter patient diseasefree periods and overall survival time, compared with those that did not grow in vitro. No correlation was found between ability to grow and clinical parameters such as TNM status, or tumour grade or site. In agreement with our results, Kim et al. established nine new permanent SCC cell lines, but their propensity to grow in vitro did not appear to be related to tumour site or grade [13]. Thus, in vitro growth, in the present study seems to be an independent prognostic factor, in concordance with other authors [10-12] although there also are reports on lack of such correlation [14]. The capacity of tumour cells to grow in vitro could be dependent on their genetic alterations. Support for this hypothesis comes from the finding that all the culturable cell lines, except for one in this study were seen to have complex karyotypes after short-term culturing. Additionally, complex karyotypes have been shown to be associated with poor prognosis [15].

We also investigated possible differences between the two tumour groups regarding DNA content, index and S-phase fraction, but no statistically significant differences were found. These cellular characteristics have been widely investigated previously, since they are assumed to reflect the loss of normal cell proliferation control and the underlying genetic abnormalities. The prognostic value of DNA content is, however, more uncertain. While some studies have found a correlation with poor outcome and higher recurrence rate in aneuploid tumours $[16,17]$, the opposite, i.e. better survival of those with non-diploid tumours, has also been reported [18]. 


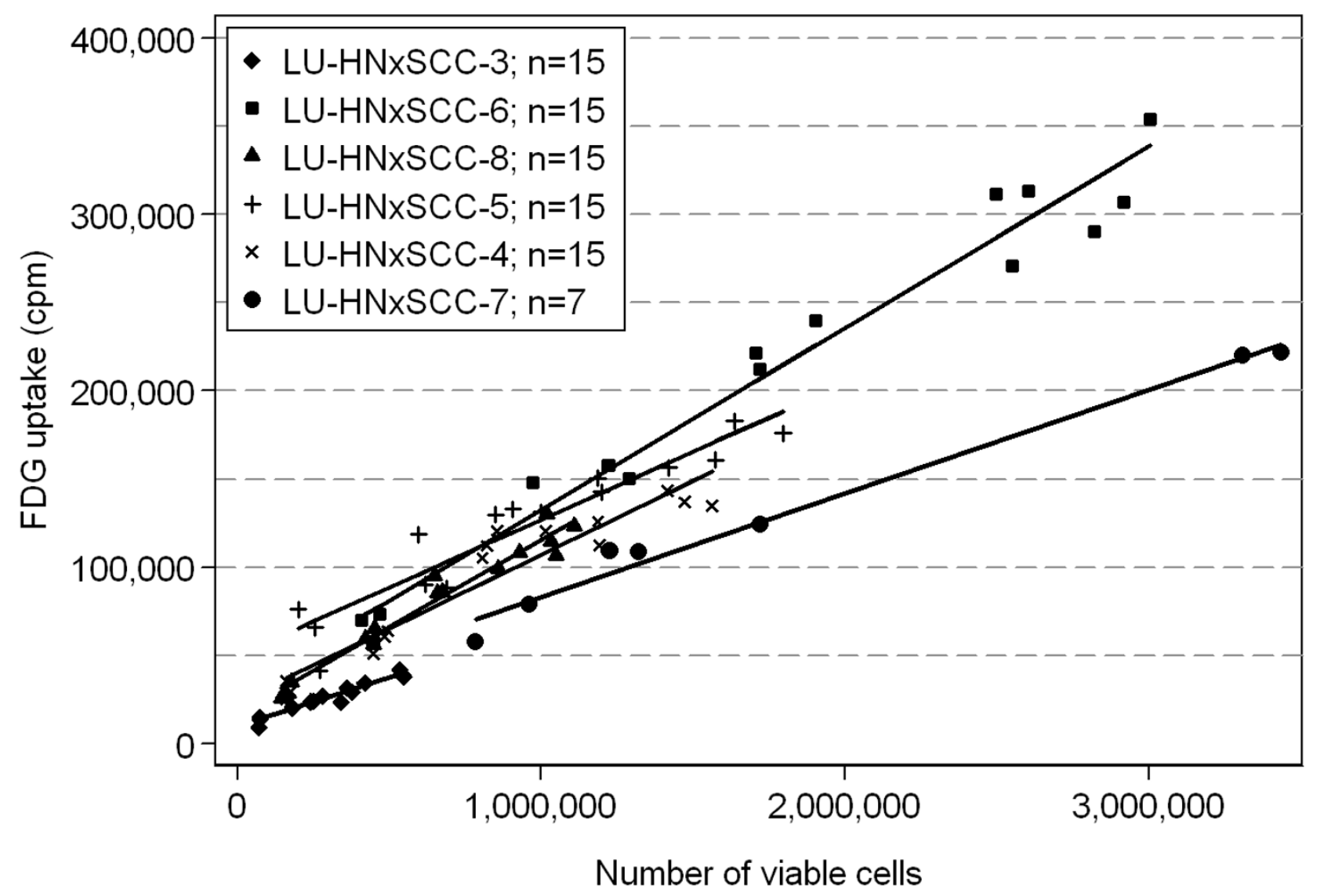

Figure 2

The I 8F-FDG uptake, expressed as counts per minute adjusted for time, versus number of viable cells present for the six cell lines, scatter plot and fitted regression lines.

The extent of 18F-FDG uptake has been suggested to provide a measure of tumour aggressiveness, and thus to be associated with poor prognosis in many tumour types $[19,20]$, including HNSCC $[21,22]$. The usefulness of $18 \mathrm{~F}-$ FDG-PET in HNSCC for detection of recurrent disease is well recognized and clinical studies have shown a capacity for PET to predict response to cytotoxic therapy $[23,24]$. We determined the 18F-FDG uptake and its relation to cell viability in the established cell lines and found an inverse correlation between cell doubling time (DT) and 18F-FDG uptake; the shorter the doubling time, the higher the 18F-FDG uptake. The correlation between the number of viable cells and 18F-FDG uptake, and between a shorter tumour doubling time and a higher 18F-FDG uptake, support a relation between 18F-FDG metabolism and tumour aggressiveness. A similar correlation between 18F-FDG uptake and cell proliferation has been described for other cancer types, including breast and colonic tumours [25]. In another in vitro study using HNSCC lines, Minn et al.[26] found a relation between 18F-FDG uptake and cell proliferation index, defined as the percentage of tumour cells in the S+G2/M phase, while Smith et al.[27] found a similar correlation with the S-phase fraction. Furthermore, in a clinical trial on 14 patients, a close correlation between growth fraction, determined by Ki67MIB-1, and PCNA, assessed with immunohistochemistry, and 18F-FDG uptake was demonstrated [28], but no correlation between 18 F-FDG uptake and DNA ploidity was seen. The close relation between CCND1 status and cell proliferation suggests that deregulated CCND1 could be a factor affecting 18F-FDG uptake. However, we found no correlation between cyclin D1 expression or CCND1 amplification and 18F-FDG uptake. Similar results, i.e. no correlation between CCND1 status and 18F-FDG uptake, have been reported in a clinical trial on lung cancer patients [29]. 


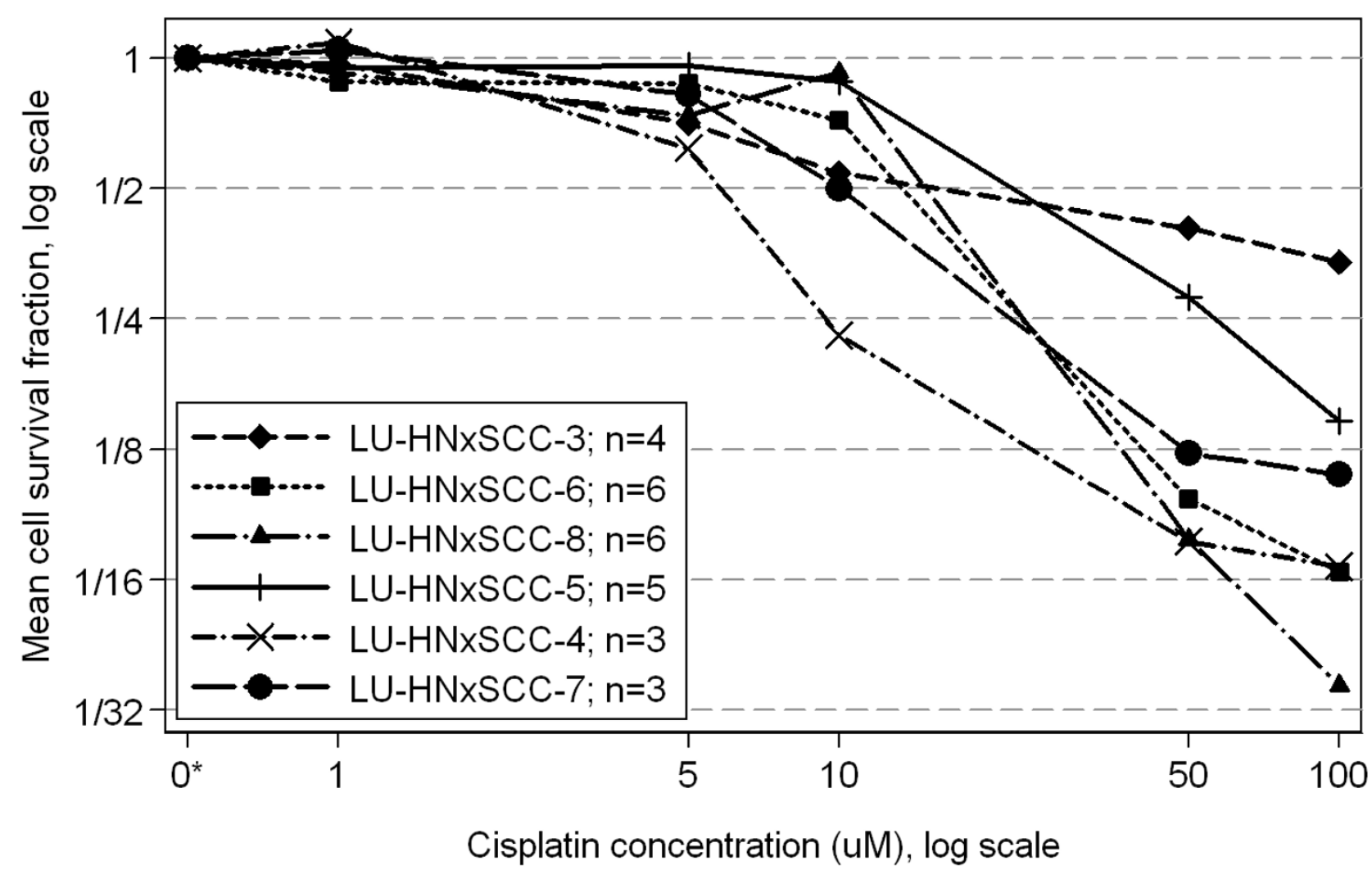

* Note: The cisplatin concentration 0 uM corresponds to minus infinity on a log scale. Thus, the $x$-axis scale is truly logartihmic only for positive concentrations.

Figure 3

Survival curves of the different cell lines exposed to varying concentrations of cisplatin obtained by crystal violet assay. Each value represents an average of at least three experiment.

Some studies have found TP53 mutations to be accompanied by increased glycolysis, which could be the result of reduced synthesis of proteins in the COX $\Pi$ subunit or increased transcription of HK-2 [30,31]. We found no association between the presence or absence of TP53 and increased 18F-FDG uptake.

To best of our knowledge, there are no previous reports on possible correlations between 18F-FDG uptake and CCND1 or TP53 status in HNSCC, although similar studies have been carried out on other tumours [29,30], demonstrating a correlation between TP53 overexpression and higher 18F-FDG uptake [30]. One reason why we did not observe any correlation between the 18F-FDG uptake and the TP53 and CCND1 status could be that the tumour cells in vitro have an excess of nutrients, and that they must be placed under stress to reveal a correlation. Therefore, the next experimental step will be to treat the cell lines with cisplatin, perhaps providing more insight into the complex and still enigmatic mechanisms behind the intracellular uptake and accumulation of 18F-FDG.

The six cell lines were also tested regarding cisplatin sensitivity. Cisplatin-induced cell death was measured using crystal violet staining, a method evaluated before [9]. A statistical difference was found between the cell lines, demonstrating the usefulness of the model for studying chemosensitivity.

\section{Conclusion}

The results in this present study support the value of tumour cell cultures as a model for prognostic and predictive studies. We found the successful establishment of an in vitro cell line from a tumour to be an independent negative prognostic marker. Furthermore, we found it feasible to study metabolic activity with 18F-FDG uptake, and 
other tumour biologic characteristics, including the chemosensitivity of the cell lines. Despite the relatively small number of tumour lines, we found a statistically significant correlation between a shorter tumour doubling time and higher 18F-FDG uptake. However, no significant difference was seen between 18F-FDG uptake and other proliferation parameters, including TP53 and CCND1 status. Although, the complex metabolic interactions between host and tumour, which create the microenvironment in vivo, will not be reproducible in cultured cell lines the growing knowledge of tumour cell characteristics will provide more understanding of the clinical behaviour of HNSCC tumours and of prognosis and therapy results for HNSCC patients.

\section{Competing interests}

The authors declare that they have no competing interests.

\section{Authors' contributions}

EH participated in the experiments in vitro, interpretation of the study and drafted the manuscript. EK conceived of the study, and participated in its design and interpretation. BB performed the flowcytometry analysis and the interpretation. $\mathrm{PB}$ performed the statistically analyses and interpretation. $\mathrm{AB}$ analysed the PCR-SSCP and DNA sequencing and interpretation. $\mathrm{EB}$ participated in the design of the study and revising the manuscript. FM evaluated and analysed the cytogenetic results. TO performed the FDG uptake measurements and interpretation. KR performed the FISH method and evaluation. JW participated in its design and coordination. PW conceived of the study, participated in its design and coordination and helped to draft the manuscript. All authors read and approved the final manuscript.

\section{Acknowledgements}

The authors want to thank Christina Boll and Margareta Ohlsson for valuable assistance with the experimental work. This study was supported by the Swedish Cancer Society (grant no. CAN 2007// 092), the King Gustaf V Jubilee Fund (grant no. 074242), governmental funding of clinical research within the Swedish health care system, the Foundations of the Lund University Hospital, Gunnar Nilsson's Cancer Foundation (grant no. WI2I/07), Fru Berta Kamprad's Foundation for Utforskning och Bekämpning av Cancersjukdomar, and Laryngfonden (grant no. 13-07).

The experiments were performed according to current Swedish legislation, and were approved by the Regional Ethics Board of Southern Sweden (LU376-0I, M48-06).

\section{References}

I. Ferley JAM, Boniol M, Heanue M, Colombet M, Boyle P: Estimates of cancer incidence and mortality in Europe in 2006. Annals of Oncology 2007, I 8:582-92.

2. Vokes EE, Weichselbaum RR, Lippman SM, Hong WK: Head and neck cancer. N Engl ] Med 1993, 3: I84-94

3. Pignon JP, Bourhis J, Domenge C, Designe L: Chemotherapy added to locoregional treatment for head and neck squamous-cell carcinoma: three meta-analyses of updated individual data. MACH-NC Collaborative Group. Meta-Analysis of Chemotherapy on Head and Neck Cancer. Lancet 2000, 355(9208):949-55.

4. Baldetorp B, Dalberg M, Holst U, Lindgren G: Statistical evaluation of cell kinetic data from DNA flow cytometry (FCM) by the EM algorithm. Cytometry 1989, 6:695-705.

5. Schutte B, Reynders MM, Bosman FT, Blijham GH: Flow cytometric determination of DNA ploidy level in nuclei isolated from paraffin-embedded tissue. Cytometry 1985, 6(1):26-30.

6. Jin C, Mertens F, Jin Y, Wennerberg J, Heim S, Mitelman F: Complex karyotype with an IIqI3 homogeneously staining region in esophageal squamous cell carcinoma. Cancer Genet Cytogenet 1995, 82(2): 175-6.

7. Tanner MM, Tirkkonen M, Kallioniemi A, Collins C, Stokke T, Karhu R, Kowbel D, Shadravan F, Hintz M, Kuo W, Waldman FM, Isola J]: Increased copy number at $20 \mathrm{ql} 3$ in breast cancer: defining the critical region and exclusion of candidate genes. Cancer Res 1994, 54(16):4257-60.

8. Fioretos T, Strombeck B, Sandberg T, Johansson B, Billstrom R, Borg A, Nilsson PG, Berghe HVD, Hagemeijer A, Mitelman F, Höglund M: Isochromosome $17 \mathrm{q}$ in blast crisis of chronic myeloid leukemia and in other hematologic malignancies is the result of clustered breakpoints in $17 \mathrm{pII}$ and is not associated with coding TP53 mutations. Blood I999, 94(I):225-32.

9. Henriksson E, Kjellen E, Wahlberg P, Wennerberg J, Kjellstrom JH: Differences in estimates of cisplatin-induced cell kill in vitro between colorimetric and cell count/colony assays. In Vitro Cell Dev Biol Anim 2006, 42( I 0):320-3.

10. Pekkola K, Raikka A, Joensuu H, Minn H, Aitasalo K, Grenman R: Permanent in vitro growth is associated with poor prognosis in head and neck cancer. Acta Otolaryngol 2004, 1 24(2): 192-6.

II. Johns ME, Mills MS: Cloning efficiency. A possible prognostic indicator in squamous cell carcinoma of head and neck. Cancer 1983, 52(8): I 40I-4.

12. Johns M: The clonal assay of head and neck tumor cells: results and clinical correlations. Laryngoscope 1982, 92(7 Pt 2 Suppl 28): I-26.

13. Kim SYCK, Lee HR, Lee KS, Carey TE: Establishment and characterization of nine new head and neck cancer cell lines. Acta Otolaryngol 1997, II 7(5):775-84.

14. Mattox DE, Von Hoff DD, Clark GM, Aufdemorte TB: Factors that influence growth of head and neck squamous carcinoma in the soft agar cloning assay. Cancer 1984, 53(8): 1736-40.

15. Akervall JA, Jin $Y$, Wennerberg JP, Zatterstrom UK, Kjellen $E$, Mertens F, Wennerberg J: Chromosomal abnormalities involving I / q / 3 are associated with poor prognosis in patients with squamous cell carcinoma of the head and neck. Cancer 1995, 76(5):853-9.

16. Arai $Y$, Tsukuda $M$, Ito $K$, Enomoto $H$, Furukawa $M$, Kubota $A$, Yanoma S, Okamoto N: Analysis of DNA ploidy using fresh frozen tissues of head and neck squamous cell carcinomas. Auris Nasus Larynx 1997, 24(2): 193-8.

17. Rubio Bueno P, Naval Gias L, Garcia Delgado R, Domingo Cebollada J. Diaz Gonzalez F]: Tumor DNA content as a prognostic indicator in squamous cell carcinoma of the oral cavity and tongue base. Head \& Neck 1998, 20(3):232-39.

18. Goldsmith MM, Cresson DH, Arnold LA, Postma DS, Askin FB, Pillsbury HC: DNA flow cytometry as a prognostic indicator in head and neck cancer. Otolaryngol Head Neck Surg 1987, 96(4):307-18.

19. Borst GR, Belderbos JS, Boellaard R, Comans EF, De Jaeger K, Lammertsma AA, Lebesque JV: Standardised FDG uptake: a prognostic factor for inoperable non-small cell lung cancer. Eur J Cancer 2005, 4 I (I I): I533-4I.

20. Sperti C, Pasquali C, Chierichetti F, Ferronato A, Decet G, Pedrazzol $S$ : I8-Fluorodeoxyglucose positron emission tomography in predicting survival of patients with pancreatic carcinoma. J Gastrointest Surg 2003, 7(8):953-9. discussion 59-60.

21. Halfpenny W, Hain SF, Biassoni L, Maisey MN, Sherman JA, McGurk M: FDG-PET. A possible prognostic factor in head and neck cancer. Br J Cancer 2002, 86(4):5 I 2-6.

22. Kunkel M, Reichert TE, Benz P, Lehr HA, Jeong JH, Wieand S, Bartenstein P, Wagner W, Whiteside TL: Overexpression of Glut-I and increased glucose metabolism in tumors are associated with a poor prognosis in patients with oral squamous cell carcinoma. Cancer 2003, 97(4): 1015-24. 
23. Brun E, Kjellen E, Tennvall J, Ohlsson T, Sandell A, Perfekt R, Wennerberg J, Strand SE: FDG PET studies during treatment: prediction of therapy outcome in head and neck squamous cell carcinoma. Head Neck 2002, 24(2): 127-35.

24. Schoder $\mathrm{H}$, Yeung HW: Positron emission imaging of head and neck cancer, including thyroid carcinoma. Semin Nucl Med 2004, 34(3): $180-97$.

25. Smith TA, Titley JC, McCready VR: Proliferation is associated with 2-deoxy-D-[I-3H]glucose uptake by T47D breast tumour and SW480 and SW620 colonic tumour cells. Nucl Med Biol I998, 25(5):48I-5.

26. Minn $H$, Joensuu $H$, Ahonen $A$, Klemi P: Fluorodeoxyglucose imaging: a method to assess the proliferative activity of human cancer in vivo. Comparison with DNA flow cytometry in head and neck tumors. Cancer 1988, $6 \mathrm{I}(9)$ : I776-8I.

27. Smith TA, Titley J: Deoxyglucose uptake by a head and neck squamous carcinoma: influence of changes in proliferative fraction. Int J Radiat Oncol Biol Phys 2000, 47(I):219-23.

28. Jacob R, Welkoborsky H], Mann W], Jauch M, Amedee R: [Fluorine18] fluorodeoxyglucose positron emission tomography, DNA ploidy and growth fraction in squamous-cell carcinomas of the head and neck. ORL J Otorhinolaryngol Relat Spec 200I, 63(5):307-13.

29. Watanabe K, Nomori H, Ohtsuka T, Naruke T, Ebihara A, Orikasa H, Yamazaki K, Uno K, Kobayashi T, Goya T: [F-1 8]Fluorodeoxyglucose positron emission tomography can predict pathological tumor stage and proliferative activity determined by $\mathrm{Ki}-67$ in clinical stage IA lung adenocarcinomas. Jpn J Clin Oncol 2006, 36(7):403-9.

30. Smith TA, Sharma RI, Thompson AM, Paulin FE: Tumor I8F-FDG incorporation is enhanced by attenuation of $P 53$ function in breast cancer cells in vitro. J Nucl Med 2006, 47(9): 1525-30.

31. Zhou S, Kachhap S, Singh KK: Mitochondrial impairment in p53deficient human cancer cells. Mutagenesis 2003, I8(3):287-92.

Publish with Bio Med Central and every scientist can read your work free of charge

"BioMed Central will be the most significant development for disseminating the results of biomedical research in our lifetime. "

Sir Paul Nurse, Cancer Research UK

Your research papers will be:

- available free of charge to the entire biomedical community

- peer reviewed and published immediately upon acceptance

- cited in PubMed and archived on PubMed Central

- yours - you keep the copyright

Submit your manuscript here:

http://www.biomedcentral.com/info/publishing_adv.asp
BioMedcentral 